Virginia Commonwealth University

VCU Scholars Compass

2006

\title{
Structural, electronic, and chemical properties of multiply iodized aluminum clusters
}

\author{
N. O. Jones \\ Virginia Commonwealth University \\ J. Ulises Reveles \\ Virginia Commonwealth University \\ S. N. Khanna \\ Virginia Commonwealth University \\ See next page for additional authors
}

Follow this and additional works at: http://scholarscompass.vcu.edu/phys_pubs

Part of the Physics Commons

Jones, N. O., Reveles, J. U., Khanna, S. N., Structural, electronic, and chemical properties of multiply iodized aluminum clusters. The Journal of Chemical Physics 124, 154311 (2006). Copyright (C) 2006 AIP Publishing LLC.

\section{Downloaded from}

http://scholarscompass.vcu.edu/phys_pubs/185

This Article is brought to you for free and open access by the Dept. of Physics at VCU Scholars Compass. It has been accepted for inclusion in Physics Publications by an authorized administrator of VCU Scholars Compass. For more information, please contact libcompass@vcu.edu. 
Authors

N. O. Jones, J. Ulises Reveles, S. N. Khanna, D. E. Bergeron, P. J. Roach, and A. W. Castleman Jr. 


\title{
Structural, electronic, and chemical properties of multiply iodized aluminum clusters
}

\author{
N. O. Jones, J. Ulises Reveles, and S. N. Khanna \\ Department of Physics, Virginia Commonwealth University, Richmond, Virginia 23284 \\ D. E. Bergeron, ${ }^{\text {a) }}$ P. J. Roach, and A. W. Castleman, Jr. ${ }^{\text {b) }}$ \\ Department of Chemistry, The Pennsylvania State University, University Park, Pennsylvania 16802 \\ and Department of Physics, The Pennsylvania State University, University Park, Pennsylvania 16802
}

(Received 6 July 2005; accepted 28 February 2006; published online 20 April 2006)

\begin{abstract}
The electronic structure, stability, and reactivity of iodized aluminum clusters, which have been investigated via reactivity studies, are examined by first-principles gradient corrected density functional calculations. The observed behavior of $\mathrm{Al}_{13} \mathrm{I}_{x}^{-}$and $\mathrm{Al}_{14} \mathrm{I}_{x}^{-}$clusters is shown to indicate that for $x \leqslant 8$, they consist of compact $\mathrm{Al}_{13}^{-}$and $\mathrm{Al}_{14}^{++}$cores, respectively, demonstrating that they behave as halogen- or alkaline earthlike superatoms. For $x>8$, the $\mathrm{Al}$ cores assume a cagelike structure associated with the charging of the cores. The observed mass spectra of the reacted clusters reveal that $\mathrm{Al}_{13} \mathrm{I}_{x}^{-}$species are more stable for even $x$ while $\mathrm{Al}_{14} \mathrm{I}_{x}^{-}$exhibit enhanced stability for odd $x(x \geqslant 3)$. It is shown that these observations are linked to the formation and filling of "active sites," demonstrating a novel chemistry of superatoms. (c) 2006 American Institute of Physics.
\end{abstract}

[DOI: $10.1063 / 1.2189218]$

\section{INTRODUCTION}

The physical and chemical properties of cluster systems at the subnanoscale are often found to differ from the bulk and display a unique dependence on size, geometry, and composition. ${ }^{1,2}$ The field of cluster science has undergone an explosive growth in activity during the last two decades, largely due to innovations in both the experimental techniques and the theoretical methods available for studying cluster behavior. On the experimental side, supersonic beams, molecular jets, and other techniques now allow synthesis, characterization, and investigation of the properties of selected clusters of any size and composition. Developments in theoretical techniques and advancements in computational resources now permit the investigation of clusters larger than heretofore possible, bringing theory to the size regime of experiment. These developments have helped us reveal the significance of experimental observations by providing information that is sometimes difficult to access experimentally. This experiment-theory synergistic effort is revealing features specific to the reduced-size dimensions and opening up new opportunities. One promising concept that has emerged is the possibility of creating new materials using atomic or compound clusters as the building blocks. ${ }^{3-5}$ If possible, this would bring the level of atomic control realized in the properties of clusters to the design of materials with desirable collective traits.

It was more than a decade ago that Khanna and Jena ${ }^{3}$ discussed the possibility of designing stable metallic clusters that could form the building blocks of solids. Their arguments were derived from two different mass spectrometric

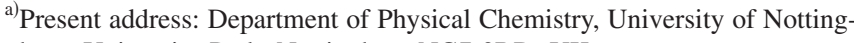
ham, University Park, Nottingham NG7 2RD, UK.

${ }^{b)}$ Electronic mail: awc@psu.edu
}

experiments on simple metal clusters. The first experiment was the observation by Knight et al. ${ }^{6}$ showing that small sodium clusters, containing 2, 8, 18, 20,34, 40, etc., atoms, were more prominent than the other sizes. Knight et al. used a simple jellium model to explain the enhanced stability at these magic numbers. In this model, one imagines that the positive charges of the free-electron metal nuclei within a cluster are evenly distributed over a sphere the size of the cluster. The energy levels for a spherical jellium potential, determined by considering all of the free electrons to be bound by this potential, have $1 s^{2} 1 p^{6} 1 d^{10} 2 s^{2} 1 f^{14} 2 p^{6}$, etc., shell closures. Like the noble gas atoms, the magic-number clusters correspond to filled electronic shells, thereby indicating the role of the total number of itinerant electrons on stability. The second experiment, relating to magic numbers in clusters that contain more than a few dozen atoms, showed that the most stable species correspond to sizes that have complete geometric shells in an icosahedral or cuboctahedral atomic arrangement. ${ }^{7}$ It would be ideal, as suggested by Khanna and Jena, if geometric close packing as well as electronic shell closure could be simultaneously achieved to enhance the stability of a cluster. ${ }^{3}$

The description of the electronic structure of clusters in terms of electronic shells raised the interesting possibility that clusters can be regarded as superatoms. There are several reasons for such an analogy. The ionization potentials of simple metal clusters exhibit local maxima at sizes corresponding to filled electronic shells, as do atoms. ${ }^{8}$ Furthermore, clusters can sometimes behave chemically similar to atomic species with like electronic valences. A proof of this concept came from the experiments by Leuchtner et al., ${ }^{9}$ who studied the reactivity of $\mathrm{Al}_{n}^{-}$clusters with oxygen. They showed that while other $\mathrm{Al}_{n}^{-}$species were etched away by oxygen, the species $\mathrm{Al}_{13}^{-}, \mathrm{Al}_{23}^{-}$, and $\mathrm{Al}_{37}^{-}$were not. Since $\mathrm{Al}_{13}^{-}$ 
has 40 valence electrons, its inertness could be understood in terms of a closed electronic shell (jellium shell closures also occur for the 23 and 37 atom aluminum cluster anions). These and other observations show that the jellium picture, though extremely simplistic and marked by indisputable limitations, is amazingly successful in describing many of the globally observed electronic features of a variety of systems, ${ }^{10}$ which allows the description of certain metallic clusters as superatoms.

It is important to emphasize that although the electronic shells are introduced through the jellium model, the existence of electronic shells in fermionic systems is known to occur for a far wider range of potentials. ${ }^{8}$ For example, the energy levels in a three dimensional harmonic oscillator, those in an intermediate and square well potential, and the energy levels in nuclei under a different class of potentials all lead to shells that would produce closings at 2, 8, 18, 20, 34, 40 , etc., electrons. In view of this, we shall use the term, "confined nearly-free-electron gas" when talking about the electronic shells and the properties of superatoms.

Recently, we reported ${ }^{4,11-14}$ an application of the superatom concept to the description of clusters of the type $\mathrm{Al}_{n} X^{-}$ $(X=\mathrm{Br}, \mathrm{I})$ and $\mathrm{Al}_{n} \mathrm{I}_{x}^{-}$. The $\mathrm{Al}_{13} \mathrm{I}^{-}$cluster was first observed to exhibit remarkable stability in acid etching experiments. Its resistance to attack by oxygen confirmed its magic character $^{4,11,12}$ and comparisons to a dihalide ion have provided a good description of the system. ${ }^{4,11,12,15}$ We have addressed the iodized clusters in which $n=13$ or 14 , showing that these series can be described, respectively, as containing halogenlike and alkaline earthlike superatom cores. ${ }^{13}$ The clusters containing a halogen-like superatom, $\mathrm{Al}_{13} \mathrm{I}_{x}^{-}$, were shown through oxygen etching experiments and density functional calculations to exhibit special stability for even values of $x$, thus allowing a direct comparison to well-known polyhalide ions of the type $X_{2 n+1}^{-}$. The crucial difference between traditional polyhalides and those containing the superhalogen $\mathrm{Al}_{13}$ is the tendency of the latter towards the addition of I atoms rather than $\mathrm{I}_{2}$ molecules. As we have noted, ${ }^{13}$ the $\mathrm{Al}_{13} \mathrm{I}_{x}^{-}$clusters are structurally more similar to fluorohalides than to other interhalogen ions. We have also treated clusters containing an alkaline earthlike superatom. ${ }^{13}$ As determined via oxygen etching experiments, $\mathrm{Al}_{14} \mathrm{I}_{x}^{-}$are stable for odd values of $x(x \geqslant 3)$. We have previously shown these species to have an $\mathrm{Al}_{14} \mathrm{I}_{3}^{-}$core and described the evolution of the clusters' properties as progressively more I atoms were present. We argued that an $\mathrm{Al}_{14}$ cluster behaves like an alkaline earth superatom.

The above work on the $\mathrm{Al}_{13} \mathrm{I}_{x}^{-}$and $\mathrm{Al}_{14} \mathrm{I}_{x}^{-}$series stressed three significant results. (1) The iodine in these clusters binds as I atoms rather than $I_{2}$ molecules. (2) The addition of I atoms can lead to the formation of "active sites" or lone pairs that are occupied by subsequent I atoms and result in even/ odd alternations of stability. (3) The $\mathrm{Al}_{13}$ and $\mathrm{Al}_{14}$ clusters can be looked upon, respectively, as forming superhalogen and alkaline earthlike cores upon which larger structures are built. The purpose of the present paper is to provide details of the low energy structures of the $\mathrm{Al}_{13} \mathrm{I}_{x}^{-}$and $\mathrm{Al}_{14} \mathrm{I}_{x}^{-}$series by critically examining the above three findings and pointing out their limitations in order to provide a greater understanding of the novel features of superatom chemistry.

Towards these objectives, we firstly compare the compact core $\mathrm{Al}_{13} \mathrm{I}_{x}^{-}$and $\mathrm{Al}_{14} \mathrm{I}_{x}^{-}$isomers previously considered in our density functional analyses with two new isomeric families having elongated cage (EC) and distorted spherical cage (DSC) geometries with similarities to previously reported structures. ${ }^{16}$ Secondly, we describe the factors that lead to a preference for the fluorohalide-like motif over a branching chain geometry. Thirdly, we provide insight into the evolution of the stability of the compact and cage structures with the number of I atoms. Fourthly, we had discussed the emergence of so called active sites or lone pairs responsible for the alteration of stability with an even or odd number of I atoms for the $\mathrm{Al}_{13} \mathrm{I}_{x}^{-}$series; does the occurrence of active sites persist with the inclusion of different isomeric families? In particular, for the $\mathrm{Al}_{14} \mathrm{I}_{x}^{-}$series (and selected EC and DSC members in $\mathrm{Al}_{13} \mathrm{I}_{x}^{-}$series) the microscopic mechanism of the creation and occupation of active sites is different from those of the compact $\mathrm{Al}_{13} \mathrm{I}_{x}^{-}$series. Fifthly, we address, in greater detail, different explanations for the stability of $\mathrm{Al}_{14} \mathrm{I}_{3}^{-}$that might emerge from basic jellium principles and explain why the alkaline earthlike scheme is physically preferred over other alternative schemes (particularly those arising from the composite jellium model first proposed by Leskiw and Castleman). ${ }^{17}$ Finally, we answer newly raised questions as to what kinds of chemistry superatoms may offer. Can they exhibit novel features not seen in true atoms? Can one make new materials using superatoms as building blocks? What kinds of properties would these new materials offer? The Periodic Table arranges elements in rows and columns; can the superatoms be regarded to form a third dimension to the Periodic Table? We hope that by addressing some of these issues, we will further clarify the foundations upon which cluster assembled nanostructured materials might be effectively designed.

\section{THEORETICAL METHODS}

The theoretical calculations were carried out using a first-principles gradient corrected density functional for exchange and correlation within a linear combination of atomic orbitals molecular orbital approach. Briefly, the molecular orbitals are expressed as a linear combination of atomic orbitals, formed from a linear superposition of Gaussian functions centered at the atomic sites in the cluster. The exchange and correlation contributions to the potential and energy were included using a gradient corrected density functional. ${ }^{18}$ The actual numerical scheme that we have used is the Naval Research Laboratory Molecular Orbital Library (NRLMOL), ${ }^{19-21}$ developed by Pederson and co-workers. In this implementation, the Hamiltonian matrix elements are evaluated by numerical integration over a mesh of points. The basis sets chosen by us have $6 s, 5 p$, and $3 d$ Gaussians for $\mathrm{Al}$ and $8 s, 7 p$, and $5 d$ Gaussians for I. The basis sets are supplemented by a $d$ function. Details of the codes and basis sets can be found in earlier papers. ${ }^{4,13,21}$ We also carried out supplementary calculations using the deMon2K software ${ }^{22}$ in order to eliminate any uncertainties associated with the 

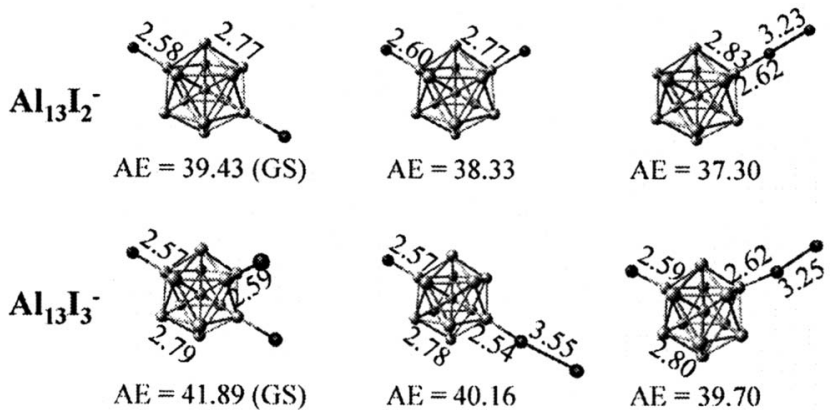

$\mathrm{AE}=39.70$

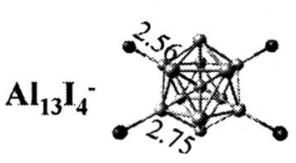

$\mathrm{AE}=45.14(\mathrm{GS})$
$\mathrm{AE}=40.16$

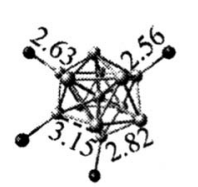

$\mathrm{AE}=44.24$

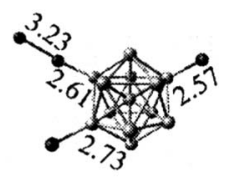

$\mathrm{AE}=42.93$

FIG. 1. Competing isomers considered for $\mathrm{Al}_{13} \mathrm{I}_{x}^{-}$. The ground state clusters are indicated by GS. Note that clusters with intact $I_{2}$ units are higher in energy. The atomization energies (AEs) are given in units of $\mathrm{eV}$ and bond lengths are in units of $\AA$.

choice of basis set or the numerical procedure. In these studies, we employed a gradient corrected density functional ${ }^{18}$ and the double zeta valence polarized (DZVP) basis set. ${ }^{23}$

\section{RESULTS AND DISCUSSION}

\section{A. $\mathrm{Al}_{13} \mathrm{I}_{x}^{-}$}

In a previous paper, we have reported for $\mathrm{Al}_{13} \mathrm{I}_{x}^{-}$the low energy structures and corresponding charge density plots for the highest occupied molecular orbitals. ${ }^{13}$ In this investigation, we had primarily focused on the structures obtained by starting from $\mathrm{Al}_{13}$ icosahedron and subsequently decorating the various surface sites with I atoms. In this work, we have extended these investigations to include the $C_{2}$ and $C_{2 v}$ cagetype families reported by Han and Jung, ${ }^{16}$ where the $\mathrm{Al}_{13}$ cores are significantly distorted. In our work, the structures are optimized without any symmetry constraint.

Before we present these results, the focus of attention is given to the $\mathrm{Al}_{13} \mathrm{I}_{x}^{-}$clusters containing two to four iodine atoms where the $\mathrm{Al}_{13}$ core has a compact structure. Do the I atoms prefer to bind atomically or in a molecular form and is there any kind of pairing between various I sites? Figure 1 depicts several alternative isomers of $\mathrm{Al}_{13} \mathrm{I}_{x}^{-}(x=2-4)$. Included are isomers that would treat $\mathrm{Al}_{13}$ as a halogen atom in conventional polyhalide molecules of the branching chain geometry. ${ }^{24}$ Polyhalides usually consist of building blocks corresponding to $X^{-}, X_{2}$, and $X_{3}^{-}$. In the $\mathrm{Al}_{13} \mathrm{I}_{x}^{-}$system, the superatom-containing analogs of these polyhalides would be $\mathrm{Al}_{13}^{-}, \mathrm{Al}_{13} \mathrm{I}^{-}$, and $\mathrm{Al}_{13} \mathrm{I}_{2}^{-}$, which have been previously treated and found to be stable. ${ }^{4,11,12}$ In a strict analogy, it should then be possible to construct "superpolyhalides" using these clusters as a core. However, calculations show that when $I_{2}$ is added to $\mathrm{Al}_{13}^{-}$or $\mathrm{Al}_{13} \mathrm{I}_{2}^{-}$, its molecular nature is not preserved; the I-I bond is broken in favor of Al-I bonds. This is clearly demonstrated in Fig. 1 which shows that the energies for isomers featuring intact $I_{2}$ are much higher than for isomers featuring I atoms bound to the $\mathrm{Al}$ cluster core (as seen in the previously reported structures ${ }^{13}$ ). This observation can be ra-

tionalized both in terms of the typical bond strengths and in terms of the reaction mechanism. The majority of clusters generated as products in the experimental studies ${ }^{13}$ are believed to be formed via etching of larger clusters according to

$$
A_{n}^{-}+\mathrm{I}_{2} \rightarrow \mathrm{Al}_{n-1} \mathrm{I}^{-}+\text {AlI. }
$$

If most of the clusters are formed by the addition of one I atom at a time, the absence of $\mathrm{I}_{2}$ units is not surprising at all. Still, this does not explain why the addition of I atoms is preferred. That is, why is an adsorption pathway not more favorable and why are members of the series that have an even number of iodine atoms more stable than those with an odd number? Examining the cluster energetics and the thermochemistry involved in the reactions, it is clear that the reaction is driven by the energetic favorability of breaking $\mathrm{I}-\mathrm{I}$ bonds and forming $\mathrm{Al}-\mathrm{I}$ bonds. Consider that All has an atomization energy (AE) of $3.83 \mathrm{eV}$, while $\mathrm{I}_{2}$ has an $\mathrm{AE}$ of only $2.21 \mathrm{eV}$. Further, the stable $\mathrm{AlI}_{3}$ molecule has an AE of $8.75 \mathrm{eV}$, meaning that each I is bound to the $\mathrm{Al}$ by about $2.92 \mathrm{eV}$; again, Al-I bonds are stronger than I-I bonds. As we will show later, this general statement proves true for all of the clusters considered here.

The structures observed show a marked departure from the branching chain configurations common to most polyhalides. ${ }^{24} \mathrm{Al}_{13} \mathrm{I}_{4}^{-}$, for example, in no way resembles $\mathrm{I}_{5}^{-}$, which has V- and T-shaped conformers. However, it is important to recall that the fluorohalides, such as $\mathrm{BrF}_{6}^{-}$, typically consist of a larger central halogen surrounded by the smaller fluorine atoms. ${ }^{25}$ These species obey the same general rule as branching chain polyhalides in that the total number of halogen atoms must be odd in order to achieve a stable anion. The primary difference between these natural interhalogens and our superatom-containing analogs is that in the case of $\mathrm{Al}_{13} \mathrm{I}_{x}^{-}$clusters, the central "halogen" (namely, $\mathrm{Al}_{13}$, whose structure is mildly perturbed in the cluster) has the greater electron affinity (EA). This, of course, is not the case in the fluorohalide family, and so the $\mathrm{Al}_{13} \mathrm{I}_{x}^{-}$"interhalides" feature bond polarity not found in any other interhalogen system of which we are aware.

With an understanding of the formation and structure of the $\mathrm{Al}_{13} \mathrm{I}_{x}^{-}$clusters, it is worth scrutinizing now the stability of the $\mathrm{Al}_{13}$ or $\mathrm{Al}_{14}$ core upon multiple addition of I atoms. As mentioned before, there are three families of structures for the $\mathrm{Al}_{13} \mathrm{I}_{x}^{-}$series, namely, the ones having a compact $\mathrm{Al}_{13}$ core (with interior $\mathrm{Al}$ atom) and the others having $\mathrm{EC}$ and DSC structures. In Fig. 2 we show the relative stability of the hollow families of structures with respect to the compact geometry for $\mathrm{Al}_{13}$. Positive energies imply less stable, while negative values indicate a more stable species. Note that for $\mathrm{Al}_{13} \mathrm{I}^{-}$, the ground state is an icosahedral structure with an I occupying an on-top site, as reported previously. ${ }^{4,5}$ The cage structures are $1.16 \mathrm{eV}$ and $0.63 \mathrm{eV}$ less stable than the compact motif. However, as the number of I atoms increases, the difference between the stability of compact and hollow structures decreases and for $\mathrm{Al}_{13} \mathrm{I}_{8}^{-}$, the two families are nearly degenerate. At higher sizes, cage structures are indeed more stable for up to $x=13$. 


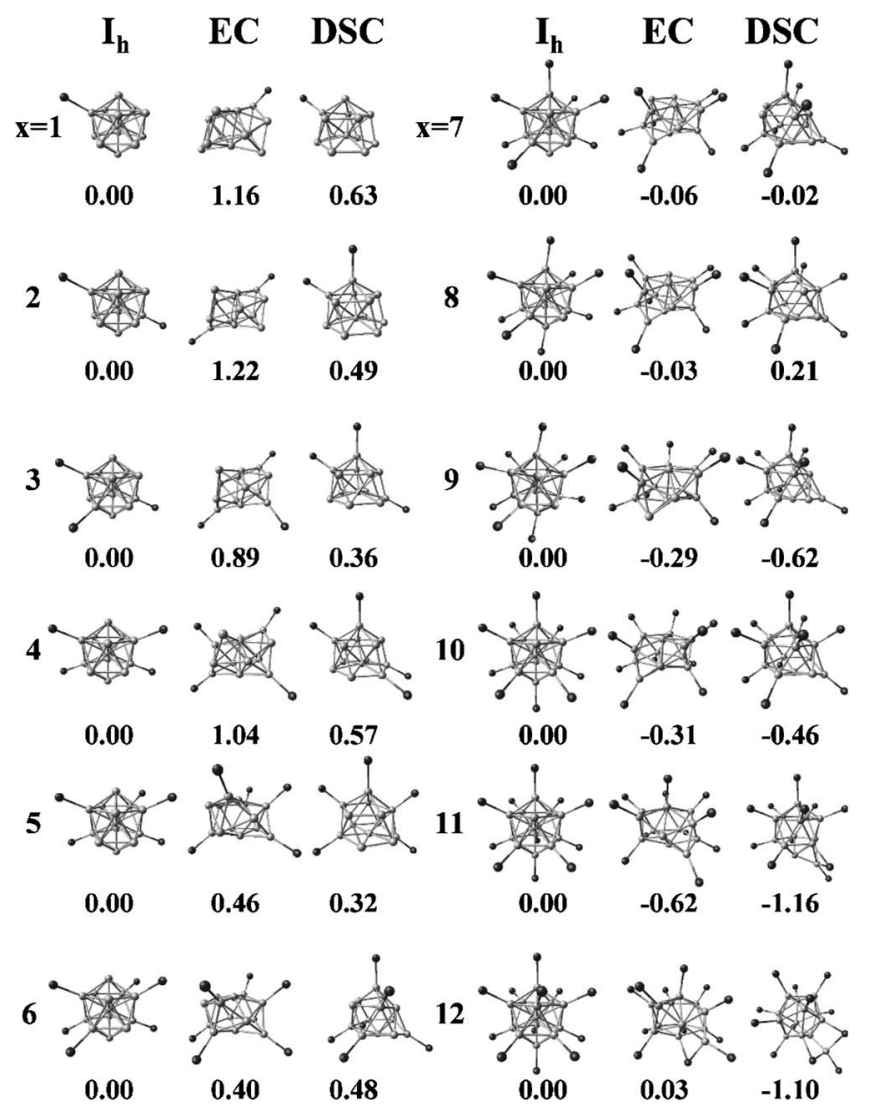

FIG. 2. Relative energies $(\mathrm{eV})$ for the $\mathrm{Al}_{13} \mathrm{I}_{x}^{-}(x=1-12)$ clusters.

In our previous paper, ${ }^{13}$ we had reported the change in energy $\Delta E_{x}$

$$
\Delta E_{x}=E\left(\mathrm{Al}_{13} \mathrm{I}_{x}^{-}\right)-E\left(\mathrm{Al}_{13} \mathrm{I}_{x-1}^{-}\right)-E(I)
$$

representing the gain in energy as successive I are added. We had shown that clusters with even numbers of I atoms are indeed more stable than the one's with odd numbers of I atoms. It is interesting to note that this alternation is unchanged by the inclusion of the new cage structures. In Fig. 3 we show the variation of $\Delta E_{x}$ including the new geometries, while Table I gives the numerical values. Note that $\mathrm{Al}_{13} \mathrm{I}_{10}^{-}$and $\mathrm{Al}_{13} \mathrm{I}_{12}^{-}$are again ${ }^{5}$ more stable than $\mathrm{Al}_{13} \mathrm{I}_{9}^{-}$and

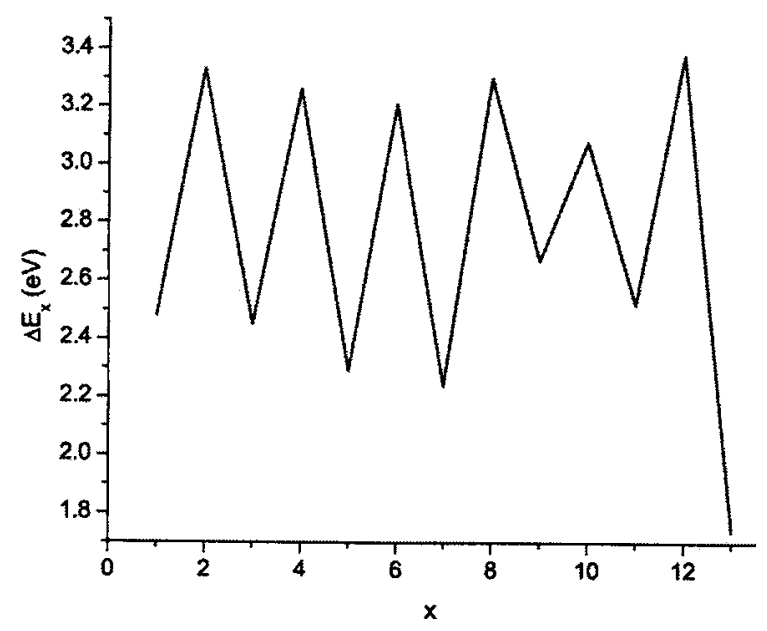

FIG. 3. $\Delta E_{x}$ for the $\mathrm{Al}_{13} \mathrm{I}_{x}^{-}(x=1-13)$ clusters.
TABLE I. Atomization energies (AEs) and the gain in energy $\Delta E_{\mathrm{I}}$ upon successive addition of $\mathrm{I}$ atoms for $\mathrm{Al}_{13} \mathrm{I}_{x}^{-}$.

\begin{tabular}{cccc}
\hline \hline Cluster & Type & $\mathrm{AE}(\mathrm{eV})$ & $\Delta E_{\mathrm{I}}$ \\
\hline $\mathrm{Al}_{13} \mathrm{I}^{-}$ & $\mathrm{I}_{h}$ & 36.11 & 2.48 \\
$\mathrm{Al}_{13} \mathrm{I}_{2}^{-}$ & $\mathrm{I}_{h}$ & 39.44 & 3.33 \\
$\mathrm{Al}_{13} \mathrm{I}_{3}^{-}$ & $\mathrm{I}_{h}$ & 41.89 & 2.45 \\
$\mathrm{Al}_{13} \mathrm{I}_{4}^{-}$ & $\mathrm{I}_{h}$ & 45.15 & 3.26 \\
$\mathrm{Al}_{13} \mathrm{I}_{5}^{-}$ & $\mathrm{I}_{h}$ & 47.44 & 2.29 \\
$\mathrm{Al}_{13} \mathrm{I}_{6}^{-}$ & $\mathrm{I}_{h}$ & 50.65 & 3.21 \\
$\mathrm{Al}_{13} \mathrm{I}_{7}^{-}$ & $\mathrm{I}_{h}$ & 52.89 & 2.24 \\
$\mathrm{Al}_{13} \mathrm{I}_{8}^{-}$ & $\mathrm{I}$ & 56.18 & 3.30 \\
$\mathrm{Al}_{13} \mathrm{I}_{9}^{-}$ & $\mathrm{DSC}$ & 58.88 & 2.67 \\
$\mathrm{Al}_{13} \mathrm{I}_{10}^{-}$ & $\mathrm{DSC}$ & 61.97 & 3.08 \\
$\mathrm{Al}_{13} \mathrm{I}_{11}^{-}$ & $\mathrm{DSC}$ & 64.48 & 2.52 \\
$\mathrm{Al}_{13} \mathrm{I}_{12}^{-}$ & $\mathrm{DSC}$ & 67.86 & 3.38 \\
$\mathrm{Al}_{13} \mathrm{I}_{13}^{-}$ & $\mathrm{DSC}$ & 69.60 & 1.74 \\
\hline \hline
\end{tabular}

$\mathrm{Al}_{13} \mathrm{I}_{11}^{-}$. We had previously reported that the physical origin of these variations lies in the generation and subsequent occupation of the "active sites." This feature also persists for the caged families of structures. To show this, we plot in Fig. 4 electronic charge density of the highest occupied molecular orbital (HOMO) for all sizes. In $\mathrm{Al}_{13} \mathrm{I}^{-}$, the I occupying the on-top site generates a lobe of the charge density at an Al site opposite to the $\mathrm{Al}$ attached to I for the compact and EC structures, while the lobe occupies a site adjacent to the I for the DSC structure. These lobes are marked by the dark arrows. Note that the I atoms in $\mathrm{Al}_{13} \mathrm{I}_{2}^{-}$occupy this active site leading to a large gain in $\Delta E_{x}$. As shown in Fig. 4, all the $\mathrm{Al}_{13} \mathrm{I}_{x}^{-}$clusters with an odd number of $\mathrm{I}$ atoms are marked by
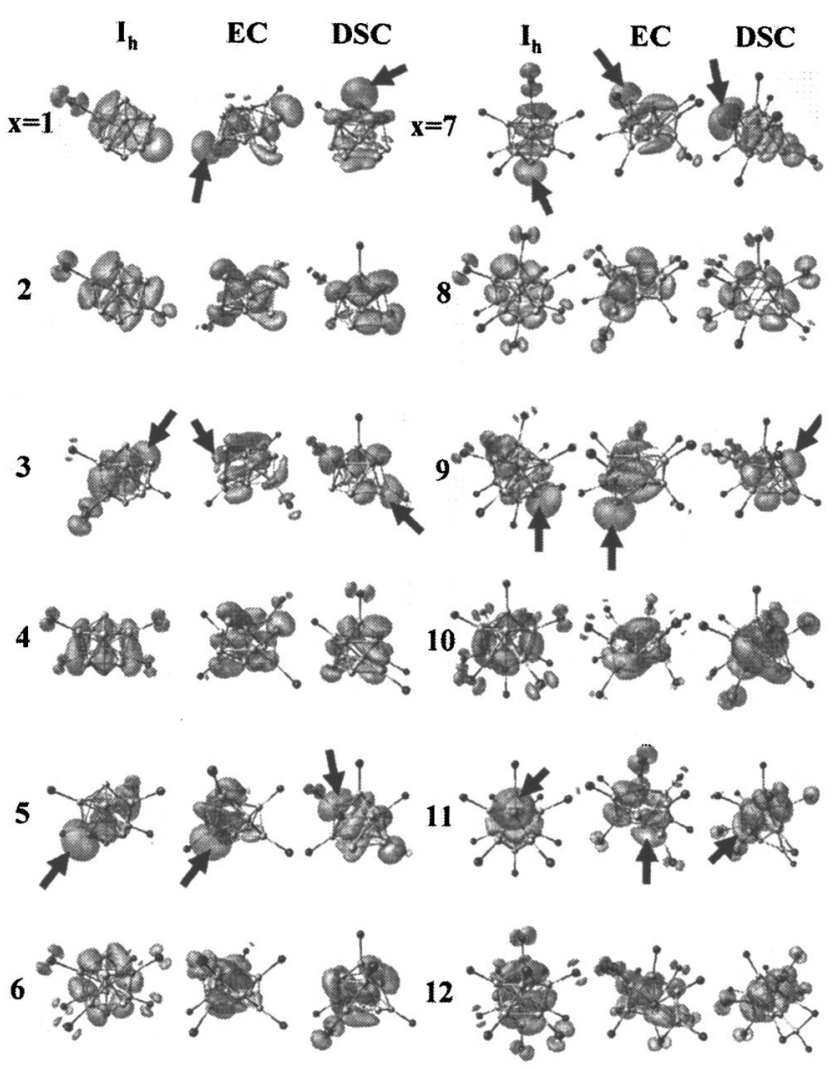

FIG. 4. HOMO charge density plots for the $\mathrm{Al}_{13} \mathrm{I}_{x}^{-}(x=1-12)$ clusters. 
such active sites that become filed by the subsequent addition of I atoms. For selected EC and DSC cases in clusters with an odd number of iodines, an iodine atom occupying a site other than the ground state geometry generates a larger active site and consequently the ground state of the subsequent even iodine cluster involves a concerted rearrangement of both atoms. We will illustrate this phenomenon later. Thus, the even/odd alternation in stability is linked to the creation and occupation of these active sites.

The progression towards the cage structures upon multiple iodine additions is probably rooted in the charging of the $\mathrm{Al}_{13}$ core. A Mulliken population analysis of the charge density indicates that the I in these structures have a Mulliken charge of around $-0.35 e^{-}$. This would imply that as one decorates the structure with multiple I atoms, the $\mathrm{Al}_{13}$ core would begin to carry a net positive charge that accounts for the stability of the cage geometries. What is significant is to realize that irrespective of the charge state the addition of successive $\mathrm{I}$ atoms to form odd $\mathrm{Al}_{13} \mathrm{I}_{x}^{-}$compounds continues to generate active sites that get occupied in structures with even numbers of I atoms indicating a novel chemistry.

\section{B. $\mathrm{Al}_{14} \mathrm{I}_{\boldsymbol{x}}^{-}$}

The $\mathrm{Al}_{14} \mathrm{I}_{x}^{-}$clusters, which we previously reported as consisting of alkaline earthlike superatoms $\left(\mathrm{Al}_{14}^{++}\right)$bound to three or more I atoms, ${ }^{13}$ are again believed to be formed according to the etching reaction in Eq. (1). However, the progression of geometries in this series upon the successive addition of I atoms presents a most interesting case of the creation and occupation of active sites and superatom chemistry. The previous observation of $\mathrm{Al}_{14} \mathrm{I}_{3}^{-}$as a product in $\mathrm{HI}$ reaction experiments ${ }^{11,12}$ and the fact that it is the first member in the $\mathrm{Al}_{14} \mathrm{I}_{x}^{-}$series strongly indicate that it is the core upon which the larger clusters are built. We, therefore, first describe our investigations of the structure of this cluster.

Various structures for $\mathrm{Al}_{14} \mathrm{I}_{3}^{-}$along with the AE's are presented in Fig. 5. In examining the structures of these clusters, the most striking feature (especially for isomers A-D) is that there is a minor perturbation to the $\mathrm{Al}_{13}$ icosahedron induced by the introduction of a 14th $\mathrm{Al}$ atom. We have already mentioned ${ }^{11}$ the stability of the AlI molecule, and if $\mathrm{Al}_{13}$ is considered a halogen, then the superatom concept should allow for the description of $\mathrm{Al}_{14}$ as $\mathrm{Al}\left(\mathrm{Al}_{13}\right)$. A natural extension of this analogy would be to describe $\mathrm{Al}_{14} \mathrm{I}_{3}^{-}$as consisting of $\mathrm{Al}\left(\mathrm{Al}_{13}\right) \mathrm{I}_{3}^{-}$, which would correspond exactly to the very stable haloaluminate ion, $\mathrm{AlI}_{4}^{-}$. As shown in Fig. 5, several configurations along these lines were considered. First, note that the exact structural analog for $\mathrm{AlI}_{4}^{-}$is represented in isomer $\mathrm{A}$; isomer $\mathrm{B}$, which (if $\mathrm{Al}_{13}$ is treated as a halogen atom) is also a closed shell molecule according to a simple Lewis dot structure analysis. ${ }^{2}$ This can be attributed to the possibility that multiple I atoms can share the burden of charge donation to the $\mathrm{Al}_{13}$ unit. Note that under this model, it is assumed that the Al-I bonds are, as in the $\mathrm{Al}_{13} \mathrm{I}_{x}^{-}$ series, polar in the direction of the Al cluster moiety.

Other geometries were also considered based on the "compound jellium model" introduced by Leskiw and Castleman in their description of $\mathrm{Al}_{n} \mathrm{C}^{-}$clusters. ${ }^{17}$ The con-

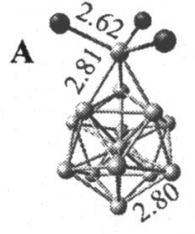

$\mathrm{AE}=44.68$
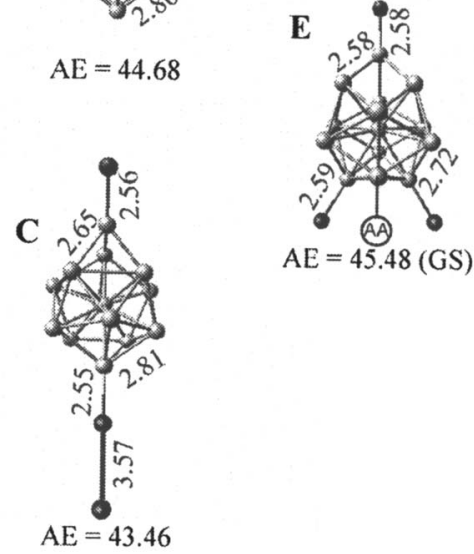

$\mathrm{Al}_{14} \mathrm{I}_{3}$

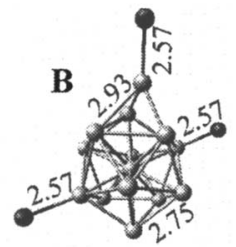

$\mathrm{AE}=44.50$

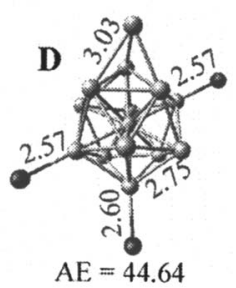

FIG. 5. Competing isomers (A-D) considered for $\mathrm{Al}_{14} \mathrm{I}_{3}^{-}$. The ground state cluster (E) is indicated by GS. The atomization energies (AEs) are given in units of $\mathrm{eV}$ and bond lengths are in units of $\AA$.

cept was introduced to explain $\mathrm{Al}_{7} \mathrm{C}^{-}$as consisting of two closed shell moieties, $\mathrm{Al}_{6}$ and $\mathrm{AlC}^{-}$, interacting via dipole polarizability interactions. The model was further extended to the description of $\mathrm{Al}_{n} \mathrm{~N}$ species. ${ }^{26-30}$ Several mechanisms can be found whereby closed shell species might be bound together to provide a stable $\mathrm{Al}_{14} \mathrm{I}_{3}^{-}$cluster: $\mathrm{Al}_{13}^{-}-\mathrm{AlI}_{3}$ (equivalent to the $\mathrm{AlI}_{4}^{-}$analog described above, isomer $\mathrm{A}$ ); $\mathrm{Al}_{13} \mathrm{I}_{2}^{-}$- AlI (similar to isomer $\mathrm{B}$, as described above); $\mathrm{Al}_{13}^{-}-\mathrm{AlI}-\mathrm{I}_{2}$ (isomer $\mathrm{C}$ ); $\mathrm{Al}_{13} \mathrm{I}-\mathrm{I}^{-}-\mathrm{AlI}$ (again, isomer $\mathrm{B}$ ), and an isomer D. Clearly, one shortcoming of the compound jellium model in this case is the sheer number of logically consistent combinations of closed shell species that lead to a molecule. As shown in Fig. 5, all of these isomers are higher in energy than the ground state structure, which can be expressed as a closed shell $\mathrm{Al}_{14}^{++}$core surrounded by three $\mathrm{I}^{-}$ ligands (Isomer $E$ ). Isomer B provides a workable motif in which the odd-even alternations in stability can be explained (an AlI molecule is attached to the $\mathrm{Al}_{13} \mathrm{I}_{x}^{-}$clusters, and subsequent I atom additions proceed as above). The calculations prove, however, that the alkaline earthlike superatom description is most consonant with the true physical situation. Significantly, the theoretical conclusions are consistent with the experimental finding that the $\mathrm{Al}_{14} \mathrm{I}_{x}^{-}$series does not appear for $x<3$.

As reported in a previous paper, ${ }^{13}$ the ground state structure [Fig. 5(E)] of $\mathrm{Al}_{14} \mathrm{I}_{3}^{-}$can be looked upon as an $\mathrm{Al}_{14}^{++}$core formed from an $\mathrm{Al}_{13}$ icosahedron where an $\mathrm{Al}-\mathrm{Al}$ bond is stretched to accommodate the 14th $\mathrm{Al}$ atom. As in the case of $\mathrm{Al}_{13}$, there exists another class of structures that resemble cages that become stable particularly at a large I content. In Fig. 6 we present findings of the lowest energy structures for each series; the electron charge density of the HOMO's for the $\mathrm{Al}_{14} \mathrm{I}_{x}^{-}$series is shown in Fig. 7. Note that for clusters containing more than eight I atoms, the cage structures become more stable than the compact geometries. Investigations were carried out for up to $x=14$, showing that the 


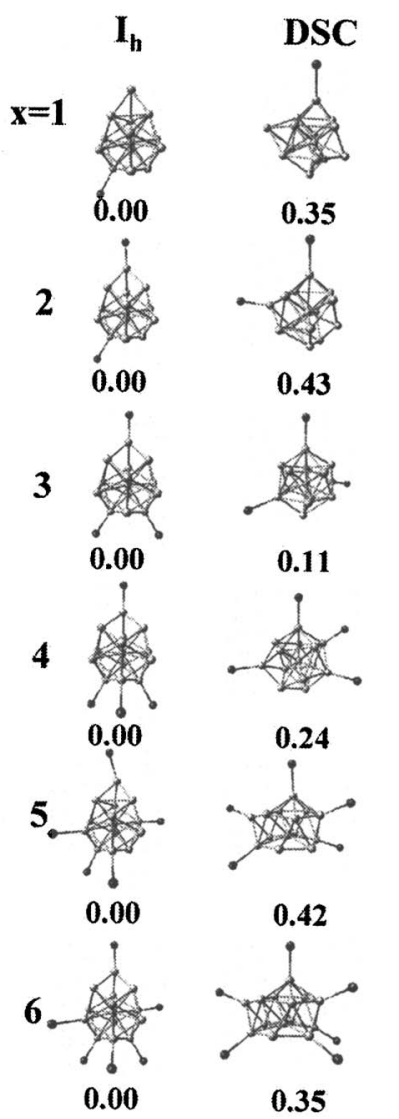

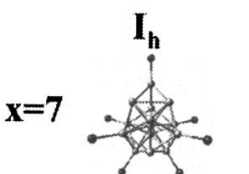

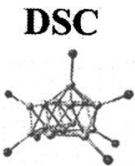

0.11

8

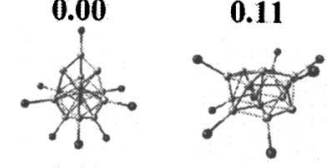

9
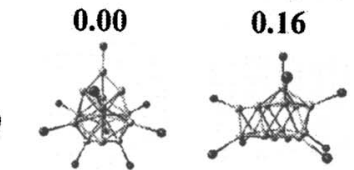

10

0.00

$-0.29$

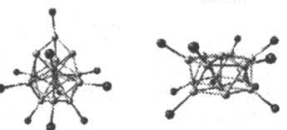

$-0.59$

0.00

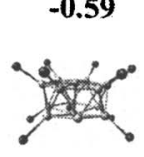

$-1.17$

12

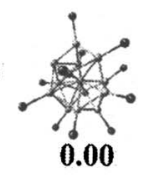

$-1.13$ $x=1$
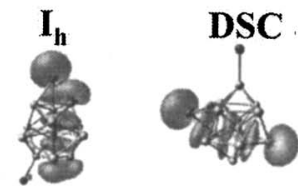

$x=7$
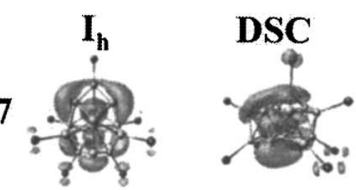

2
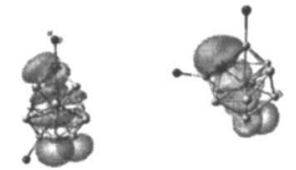

3
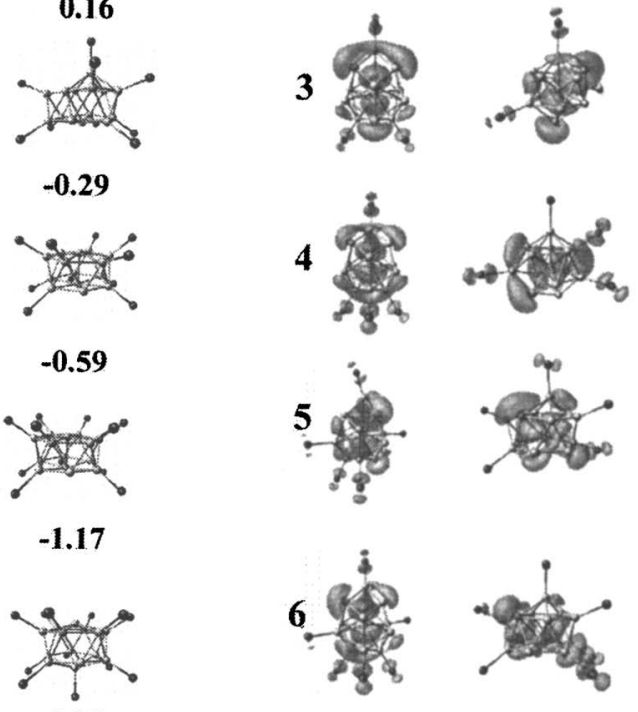

FIG. 6. Relative energies (eV) for the $\mathrm{Al}_{14} \mathrm{I}_{x}^{-}(x=1-12)$ clusters.

ground state geometries of $\mathrm{Al}_{14} \mathrm{I}_{13}^{-}$and $\mathrm{Al}_{14} \mathrm{I}_{14}^{-}$are also of the DSC type. Figure 8 shows the variations in $\Delta E_{x}$

$$
\Delta E_{x}=E\left(\mathrm{Al}_{14} \mathrm{I}_{x}^{-}\right)-E\left(\mathrm{Al}_{14} \mathrm{I}_{x-1}^{-}\right)-E(\mathrm{I}) \text { for } x \geqslant 2 .
$$

The electron affinity of $\mathrm{Al}_{14}$ is less than that for $\mathrm{I}$, thus $\Delta E_{1}=E\left(\mathrm{Al}_{14} \mathrm{I}^{-}\right)-E\left(\mathrm{Al}_{14}\right)-E\left(\mathrm{I}^{-}\right)$is used to describe the dissociation energy of $\mathrm{I}^{-}$from the $\mathrm{Al}_{14} \mathrm{I}^{-}$. Table II gives the numerical values. For the 14 aluminum atom series, as reported before, ${ }^{5}$ the clusters containing odd numbers of I are more stable than the one's containing even numbers of I atoms.

The origin of the odd-even alternations in stability is intriguing. Here, the alternations do not begin until the $\mathrm{Al}_{14}$ moiety is surrounded by three I atoms; that is, until it is able to assume the dication structure [Fig. 5(E)]. The I atom at the available active site $(A A)$ is not as strongly bound as the paired I atoms, and so the pairing effect is observed as before with the emergence and quenching of active centers as is seen by the evolving structures in Fig. 6. One of the I atoms is bound to this 14th $\mathrm{Al}$ atom, while the remaining two I atoms occupy two of the three sites in the lower triangle opposite to the 14th Al [see Fig. 5(E)]. The third site of the triangle acts as a small active site ${ }^{13}$ that can be possibly occupied by an I atom. Indeed, starting from $\mathrm{Al}_{14} \mathrm{I}_{3}^{-}$[Fig. $5(\mathrm{E})]$, the next iodine occupies the vacant site of the lower triangle in $\mathrm{Al}_{14} \mathrm{I}_{3}^{-}$, thus filling the $A A$ and forming the ground state of $\mathrm{Al}_{14} \mathrm{I}_{4}^{-}$. This site is occupied in all clusters with even numbers of I atoms and plays a critical role in the further

FIG. 7. HOMO charge density plots for the $\mathrm{Al}_{14} \mathrm{I}_{x}^{-}(x=1-12)$ clusters.

progression of the cluster. To illustrate this interesting phenomenon, we show in Fig. 9 the progression of the structures, the charge densities of the highest occupied molecular orbital, and the gain in energy in each step. Starting at $\mathrm{Al}_{14} \mathrm{I}_{4}^{-}$, the additional I occupies one of the available sites around the distorted $\mathrm{Al}_{13}$ motif forming $\mathrm{Al}_{14} \mathrm{I}_{5}^{-}$. The binding energy of the additional $\mathrm{I}$ is $2.48 \mathrm{eV}$. However, the I also generates a lobe of charge density (called the active site) at the opposite $\mathrm{Al}$ site as was previously illustrated in case of $\mathrm{Al}_{13}^{-}$. The I that occupies the AA site in the lower triangle now moves to this site, leading to a gain of $0.60 \mathrm{eV}$ in binding energy to $\mathrm{Al}$ and leaving behind a smaller active site on the triangle,

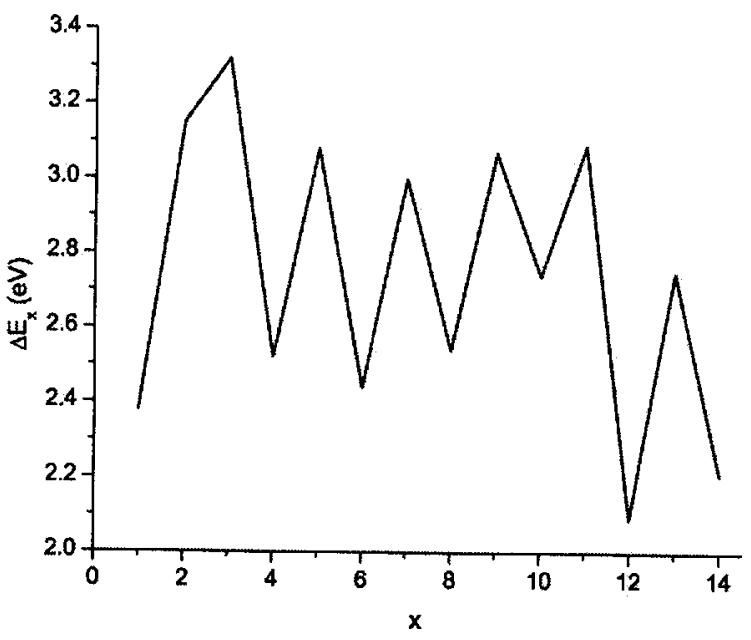

FIG. 8. $\Delta E_{x}$ for the $\mathrm{Al}_{14} \mathrm{I}_{x}^{-}(x=1-14)$ clusters. 
TABLE II. Atomization energies (AEs) and the gain in energy $\Delta E_{\mathrm{I}}$ upon successive addition of $\mathrm{I}$ atoms for $\mathrm{Al}_{14} \mathrm{I}_{x}^{-}$.

\begin{tabular}{cccc}
\hline \hline Cluster & Cluster & $\mathrm{AE}(\mathrm{eV})$ & $\Delta E_{\mathrm{I}}$ \\
\hline $\mathrm{Al}_{14} \mathrm{I}^{-}$ & $\mathrm{I}_{h}$ & 39.01 & 2.38 \\
$\mathrm{Al}_{14} \mathrm{I}_{2}^{-}$ & $\mathrm{I}_{h}$ & 42.16 & 3.15 \\
$\mathrm{Al}_{14} \mathrm{I}_{3}^{-}$ & $\mathrm{I}_{h}$ & 45.48 & 3.32 \\
$\mathrm{Al}_{14} \mathrm{I}_{4}^{-}$ & $\mathrm{I}_{h}$ & 48.00 & 2.52 \\
$\mathrm{Al}_{14} \mathrm{I}_{5}^{-}$ & $\mathrm{I}_{h}$ & 51.08 & 3.08 \\
$\mathrm{Al}_{14} \mathrm{I}_{6}^{-}$ & $\mathrm{I}_{h}$ & 53.52 & 2.44 \\
$\mathrm{Al}_{14} \mathrm{I}_{7}^{-}$ & $\mathrm{I}_{h}$ & 56.52 & 3.00 \\
$\mathrm{Al}_{14} \mathrm{I}_{8}^{-}$ & $\mathrm{I}$ & 58.96 & 2.44 \\
$\mathrm{Al}_{1} \mathrm{I}_{9}^{-}$ & $\mathrm{DSC}$ & 62.02 & 3.07 \\
$\mathrm{Al}_{14} \mathrm{I}_{10}^{-}$ & $\mathrm{DSC}$ & 64.76 & 2.74 \\
$\mathrm{Al}_{14} \mathrm{I}_{11}^{-}$ & $\mathrm{DSC}$ & 67.85 & 3.09 \\
$\mathrm{Al}_{14} \mathrm{I}_{12}^{-}$ & $\mathrm{DSC}$ & 69.94 & 2.09 \\
$\mathrm{Al}_{14} \mathrm{I}_{13}^{-}$ & $\mathrm{DSC}$ & 72.69 & 2.75 \\
$\mathrm{Al}_{14} \mathrm{I}_{14}^{-}$ & $\mathrm{DSC}$ & 74.90 & 2.21 \\
\hline \hline
\end{tabular}

which leads to the ground state of $\mathrm{Al}_{14} \mathrm{I}_{5}^{-}$. The next I then occupies the AA site in the lower triangle with a gain in energy of $2.46 \mathrm{eV}$. The process then repeats itself upon the addition of the next I. As mentioned before, selected members of the EC and DSC $\mathrm{Al}_{13} \mathrm{I}_{x}^{-}$series also exhibit similar rearrangements in going from odd to even number of I atoms. What is important to realize is that the even-odd alternations in the stability of $\mathrm{Al}_{14} \mathrm{I}_{x}^{-}$are again rooted in the formation and occupation of the active sites much in the same way as in $\mathrm{Al}_{13} \mathrm{I}_{x}^{-}$. As mentioned above, $\mathrm{Al}_{14}$ can be described as an alkaline earthlike superatom.

The even-odd alternations in the stability of $\mathrm{Al}_{13} \mathrm{I}_{x}^{-}$and $\mathrm{Al}_{14} \mathrm{I}_{x}^{-}$clusters and the initial formation of the $\mathrm{Al}_{14}^{++}$core in $\mathrm{Al}_{14} \mathrm{I}_{x}^{-}$can also be seen through features in the electronic spectrum. As ever, clusters with large HOMO-LUMO (lowest unoccupied molecular orbital) gaps exhibit enhanced stability. Within a simple jellium picture, one expects that the

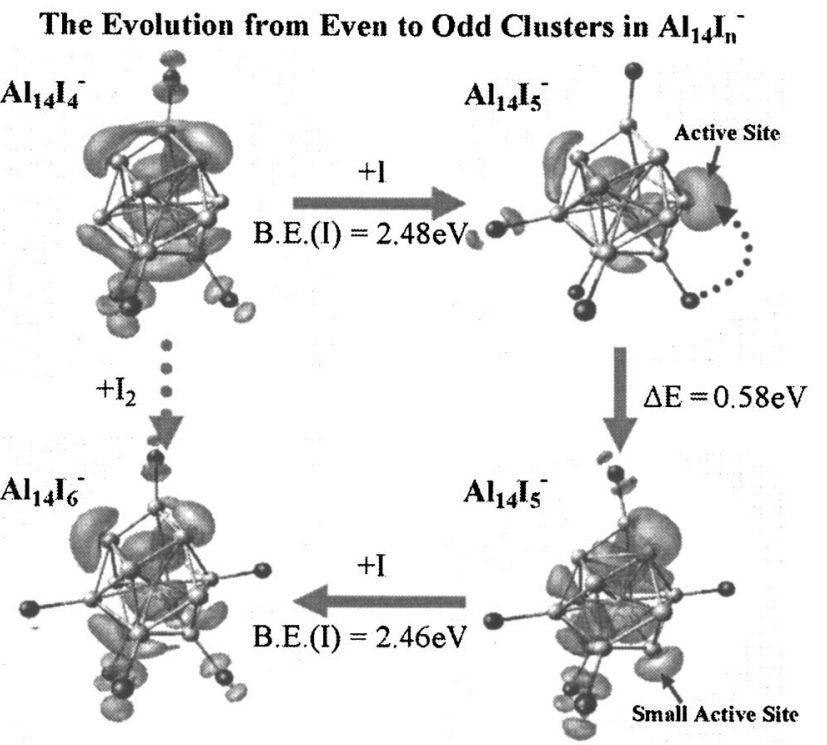

FIG. 9. Generation and annihilation mechanism for the active sites in $\mathrm{Al}_{14} \mathrm{I}_{x}^{-}$ The binding energy of the additional I, BE (I), is given as well as the gain in binding energy $\Delta E$ upon spatial relocation of the 1 atom. All energies are given in $\mathrm{eV}$.
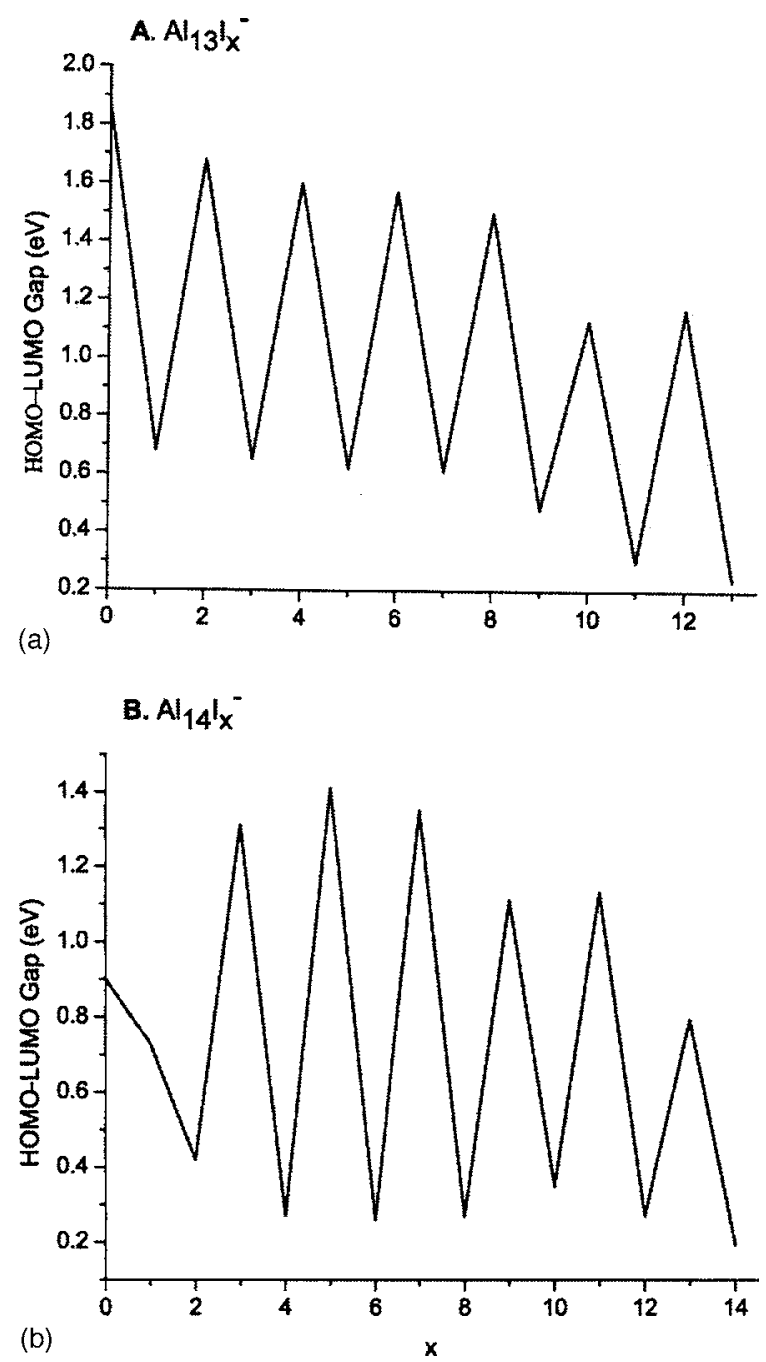

FIG. 10. HOMO-LUMO gap for the $\mathrm{Al}_{13} \mathrm{I}_{x}^{-}(x=1-13)$ and $\mathrm{Al}_{14} \mathrm{I}_{x}^{-}$ $(x=1-14)$ clusters.

HOMO-LUMO gap is large at shell closings. ${ }^{6,10}$ In Fig. 10, we have shown the HOMO-LUMO gap in $\mathrm{Al}_{13} \mathrm{I}_{x}^{-}$and $\mathrm{Al}_{14} \mathrm{I}_{x}^{-}$ clusters as a function of the number of I atoms. For the case of $\mathrm{Al}_{13} \mathrm{I}_{x}^{-}$, the clusters with an odd number of I atoms have smaller HOMO-LUMO gaps, while those with even I have larger gaps consistent with the empirical stability trends. In the case of $\mathrm{Al}_{14} \mathrm{I}_{x}^{-}$, however, note that the gap for the first two I atoms is small and it takes three I atoms to generate a large gap consistent with a shell closing. After that, the even-odd alternations continue with clusters containing an odd number of I atoms exhibiting greater stability.

\section{CONCLUSIONS}

The electronic and chemical stabilities of $\mathrm{Al}_{n} \mathrm{I}_{x}^{-}$clusters $(n=13,14)$ have been treated by state-of-the-art density functional calculations. Various isomers were examined within both the $\mathrm{Al}_{13} \mathrm{I}_{x}^{-}$and $\mathrm{Al}_{14} \mathrm{I}_{x}^{-}$families, and the lowest energy structures for $x \leqslant 8$ were found to feature superatom cores. Subsequent additions of I atoms are shown to result in the creation and quenching of active sites for all considered isomers, thus recreating the experimentally observed ${ }^{13}$ oddeven trends in stability. The core for the $\mathrm{Al}_{13} \mathrm{I}_{x}^{-}$series is an 
$\mathrm{Al}_{13}^{-}$cluster, which can be treated as the superatom equivalent of a halide ion. The core for the $\mathrm{Al}_{14} \mathrm{I}_{x}^{-}$series is similar to an $\mathrm{Al}_{14}^{++}$cluster, which acts as an alkaline earthlike superatom and requires the initial addition of three $\mathrm{I}$ atoms to the $\mathrm{Al}_{14}^{-}$ motif. Further addition of I atoms to the $\mathrm{Al}_{14}^{++}$motif leads to odd-even alternations in stability through the exchange of I atoms between stronger and weaker active sites. Consideration of the implications of the superatom concept promises to open new and fruitful synthetic pathways to cluster assembled nanostructured materials.

\section{ACKNOWLEDGMENTS}

One of the authors (N.O.J.) gratefully acknowledges support from the U.S. Department of Energy Grant No. DEFG02-96ER45579, while five of the authors (J.U.R., S.N.K., D.E.B., P.J.R., and A.W.C.) gratefully acknowledge financial support from the U.S. Department of Energy Grant No. DEFG02-02ER46009. One of the authors (D.E.B) is grateful to T. G. Wright and A. J. Stace for current support.

${ }^{1}$ Quantum Phenomena in Clusters and Nanostructures, edited by S. N. Khanna and A. W. Castleman, Jr. (Springer, New York, 2003).

${ }^{2}$ Small Particles and Inorganic Clusters, edited by H. H. Anderson (Springer, New York, 1997).

${ }^{3}$ S. N. Khanna and P. Jena, Phys. Rev. Lett. 69, 1664 (1992); H. Shinohara, Rep. Prog. Phys. 63, 843 (2000).

${ }^{4}$ D. E. Bergeron, A. W. Castleman, Jr., T. Morisato, and S. N. Khanna, Science 304, 84 (2004).

${ }^{5}$ D. E. Bergeron, A. W. Castleman, Jr., N. O. Jones, and S. N. Khanna, Nano Lett. 4, 261 (2004).

${ }^{6}$ W. D. Knight, K. Clememger, W. A. de Heer, W. A. Saunders, M. Y. Chou, and M. L. Cohen, Phys. Rev. Lett. 52, 2141 (1984).

${ }^{7}$ T. P. Martin, T. Bergmann, H. Gohlich, and T. Lange, Chem. Phys. Lett. 172, 209 (1990).

${ }^{8}$ W. A. de Heer, W. D. Knight, M. Y. Chou, and M. L. Cohen, Solid State Phys. 40, 93 (1987).

${ }^{9}$ R. E. Leuchtner, A. C. Harms, and A. W. Castleman, Jr., J. Chem. Phys.
91, 2753 (1989).

${ }^{10}$ W.-D. Schone, W. Ekardt, and J. M. Pacheco, Phys. Rev. B 50, 11079 (1994).

${ }^{11}$ D. E. Bergeron, A. W. Castleman, Jr., N. O. Jones, and S. N. Khanna, J. Chem. Phys. 121, 10456 (2004).

${ }^{12}$ D. E. Bergeron, Ph.D. thesis, The Pennsylvania State University, 2004.

${ }^{13}$ D. E. Bergeron, P. J. Roach, A. W. Castleman, Jr., N. O. Jones, and S. N. Khanna, Science 307, 231 (2005).

${ }^{14}$ D. E. Bergeron, P. J. Roach, A. W. Castleman, Jr., N. O. Jones, J. U. Reveles, and S. N. Khanna, J. Am. Chem. Soc. 127, 16048 (2005).

${ }^{15}$ Y.-K. Han and J. Jung, J. Chem. Phys. 121, 8500 (2004).

${ }^{16}$ Y.-K. Han and J. Jung, J. Chem. Phys. 123, 101102 (2005).

${ }^{17}$ B. D. Leskiw and A. W. Castleman, Jr., Chem. Phys. Lett. 316, 31 (2000).

${ }^{18}$ J. P. Perdew, K. Burke, and M. Irnzerhof, Phys. Rev. Lett. 77, 3865 (1996).

${ }^{19}$ M. R. Pederson and K. A. Jackson, Phys. Rev. B 41, 7453 (1990).

${ }^{20}$ K. A. Jackson and M. R. Pederson, Phys. Rev. B 42, 3276 (1990).

${ }^{21}$ D. V. Porezag and M. R. Pederson, Phys. Rev. A 60, 2840 (1999).

${ }^{22}$ A. M. Köster, P. Calaminici, R. Flores-Moreno et al., deMon2K (NRC, Canada, 2003).

${ }^{23}$ N. Godbout, D. R. Salahub, J. Andzelm, and E. Wimmer, Can. J. Chem. 70, 560 (1992).

${ }^{24}$ P. H. Svensson and L. Kloo, Chem. Rev. (Washington, D.C.) 103, 1649 (2003).

${ }^{25}$ C. Pak, Y. Xie, T. J. Van Huis, and H. F. Schaefer, III, J. Am. Chem. Soc. 120, 11115 (1998)

${ }^{26}$ B. D. Leskiw, A. W. Castleman, Jr., C. Ashman, and S. N. Khanna, J. Chem. Phys. 114, 1165 (2001).

${ }^{27}$ Alternative explanations of the stability of the $\mathrm{Al}_{7} \mathrm{C}^{-}$and $\mathrm{Al}_{7} \mathrm{~N}$ have been debated in the literature. While we do not intend to resolve here whether the origin of the stability exhibited by $\mathrm{Al}_{7} \mathrm{C}^{-}$and $\mathrm{Al}_{7} \mathrm{~N}$ is related to any compound jellium structure. The type of binding implied by this model and the general concepts of building molecules from closed shell jellium species are certainly relevant to the systems presently under consideration.

${ }^{28}$ H. Kawamata, Y. Negishi, A. Nakajima, and K. Kaya, Chem. Phys. Lett. 337, 255 (2001).

${ }^{29}$ J. Zhao, B. Liu, H. Zhai, R. Zhou, G. Ni, and Z. Xu, Solid State Commun. 122, 543 (2002).

${ }^{30}$ Q. Sun, Q. Wang, X. G. Gong, V. Kumar, and Y. Kawazoe, Eur. Phys. J. D 18, 77 (2002). 